\title{
Bariatric Surgery in Patients with Ventricular Assist Devices: Is it Worth the Risk?
}

\author{
Brian J Shea, Seyed Mohammad Kalantar Motamedi, Rami R Mustafa, Anuja L Sarode, Stephen \\ Masnyj, Leena Khaitan and Mujjahid Abbas* \\ Department of Surgery, USA
}

*Corresponding author: Mujjahid Abbas, Department of Surgery, University Hospitals Cleveland Medical Center, Cleveland, Ohio, USA

\begin{tabular}{|c|c|}
\hline ARTICLE INFO & ABSTRACT \\
\hline Received: 慧 October 22, 2019 & Citation: Brian J Shea, Seyed Mohammad Kalantar Motamedi, Rami R Mustafa, Anuja L \\
\hline Published: 慧 October 31, 2019 & $\begin{array}{l}\text { Sarode, Stephen Masnyj, Leena Khaitan, Mujjahid Abbas. Bariatric Surgery in Patients } \\
\text { with Ventricular Assist Devices: Is it Worth the Risk?. Biomed J Sci \& Tech Res 22(3)- } \\
\text { 2019. BJSTR. MS.ID.003749. }\end{array}$ \\
\hline
\end{tabular}

\section{Short Communication}

Bariatric surgery has been demonstrated to be superior to medical therapy for weight loss in morbidly obese patients [1] Obesity in patients undergoing cardiac surgery has been associated with increased rates of sternal wound infection [2,3] renal failure and 30-day mortality [3]. A recent study demonstrated that obesity was associated with higher morbidity, mortality and cost in patients undergoing cardiac surgery [4]. Bariatric surgery is starting to be utilized to decrease perioperative morbidity and mortality for other procedures. Through bariatric surgery, obesity is a potentially modifiable risk factor, and decreased preoperative weight can improve outcomes from a cardiac standpoint. Additionally, in patients with heart failure, weight loss has been demonstrated to improve cardiac function [5]. Patients with ventricular assist devices (VAD) pose a challenge, as these patients require therapeutic anticoagulation and can only have minimal interruption in their anticoagulation therapy. In this case series, we detail five VAD patients that underwent bariatric surgery and their outcomes related to bleeding complications. For a summary of the patients in this case series, please refer to Table 1.

Table 1: The five patients in this case series, perioperative management and bleeding complications.

\begin{tabular}{|c|c|c|c|c|c|c|c|c|c|}
\hline Patient & Sex & Age & BMI & Operation & $\begin{array}{l}\text { Chronic } \\
\text { Anticoagulant }\end{array}$ & $\begin{array}{c}\text { Days before Procedure } \\
\text { Chronic Medication Stopped }\end{array}$ & $\begin{array}{l}\text { Perioperative } \\
\text { Anticoagulant }\end{array}$ & $\begin{array}{l}\text { Interruption in } \\
\text { Therapy }\end{array}$ & $\begin{array}{c}\text { Bleeding } \\
\text { Complications }\end{array}$ \\
\hline 1 & M & 45 & 45.8 & $\begin{array}{c}\text { Sleeve } \\
\text { gastrectomy }\end{array}$ & Coumadin & 6 days & IV Heparin & 4 hours & None \\
\hline 2 & $\mathrm{~F}$ & 48 & 45.0 & $\begin{array}{c}\text { Sleeve } \\
\text { gastrectomy }\end{array}$ & Coumadin & 6 days & IV Heparin & 4 hours & None \\
\hline 3 & M & 20 & 45.0 & $\begin{array}{l}\text { Sleeve } \\
\text { gastrectomy }\end{array}$ & Coumadin & 7 days & IV Heparin & 4 hours & None \\
\hline 4 & $\mathrm{~F}$ & 43 & 40.7 & $\begin{array}{c}\text { Sleeve } \\
\text { gastrectomy }\end{array}$ & $\begin{array}{l}\text { Coumadin, } \\
\text { Plavix }\end{array}$ & 5 days & IV Heparin & 4 hours & None \\
\hline 5 & M & 58 & 44.7 & $\begin{array}{c}\text { Sleeve } \\
\text { gastrectomy }\end{array}$ & Coumadin & 5 days & IV Heparin & 4 hours & None \\
\hline
\end{tabular}

\section{Methods}

The institutional database for the MBSAQIP was analyzed for patients who underwent bariatric surgery from January 1st, 2012 to January 1st, 2018. The database was also searched for all patients that had a VAD in place at time of surgery. A chart review was then performed to identify demographic information, baseline conditions, perioperative information and outcomes in the five patients that had a VAD at the time of their surgery. 


\section{Case 1}

45-year-old male patient was seen in the outpatient bariatric office for evaluation for bariatric surgery. He was being evaluated for a cardiac transplant and had a LVAD placed approximately 10 months prior to initial evaluation. He was brought into the hospital by the cardiology team one week prior to his operation, taken off Coumadin and started on therapeutic intravenous heparin. The heparin was stopped 6 hours prior to the operation, and he underwent a laparoscopic sleeve gastrectomy, which proceeded uneventfully. Anticoagulation was restarted 4 hours after his operation with IV heparin. The patient suffered no bleeding complications. On the fifth post-operative day the patient went into sudden onset renal failure and was febrile. UGI demonstrated a possible small contained leak. The patient was taken back to the operating room, and no perforation or contamination was identified. A stent was placed endoscopically in the area of the concerning finding on the upper GI series. The patient recovered well after this operation and was discharged home after becoming therapeutic on Coumadin. The patient lost 93 pounds after his operation in 6 months, decreasing his BMI from 45.8 to 30.8. The patient then underwent successful orthotopic heart transplant.

\section{Case 2}

48-year-old female patient was seen in the outpatient clinic for evaluation. The patient had undergone LVAD placement approximately 8 months prior to evaluation. The patient was brought into the hospital one week prior to her operation by the cardiology team, her Coumadin was stopped 6 days prior to her operation and was started on IV heparin. The heparin was stopped 6 hours prior to her procedure and she underwent an uneventful laparoscopic sleeve gastrectomy. The heparin was restarted 4 hours after the procedure. She suffered no bleeding complications. The patient had her Coumadin restarted and remained in the hospital on IV heparin until her international normalized ratio (INR) was therapeutic and was subsequently discharged home. She lost a total of 47 pounds, reducing her BMI from 45.0 to 36.1. She underwent successful orthotopic heart transplant three years after her bariatric surgery.

\section{Case 3}

20-year-old male patient was seen for evaluation in the bariatric clinic. The patient had an LVAD placed for chronic ventricular failure from dilated cardiomyopathy related to a Coxsackie virus myocarditis approximately five months prior to evaluation. The patient was admitted electively one week prior to his planned bariatric procedure by the cardiology team and transitioned from Coumadin to a heparin infusion. Surgery was put off until hospital day 12 due to runs of non-sustained ventricular tachycardia. The patient did eventually undergo an uneventful laparoscopic sleeve gastrectomy after being off heparin for 6 hours. Heparin was restarted four hours after the procedure. The patient suffered no bleeding events, had his Coumadin restarted, and was discharged after he was therapeutic on Coumadin on the fifth post-operative day. The patient lost 70 pounds, decreasing his BMI from 45.1 to 35.0. One year following his procedure his ejection fraction had increased from $15 \%$ immediately preoperatively to $40-45 \%$.

\section{Case 4}

43-year-old male presented as outpatient for evaluation for bariatric surgery. He had a LVAD placed approximately 3 years before evaluation for non-ischemic cardiomyopathy. The patient was admitted to the hospital five days prior to the procedure by the cardiology team and transitioned from Coumadin to a heparin infusion. The heparin was stopped 6 hours prior to the procedure and restarted 4 hours after the procedure. There were no bleeding complications, and the patient was discharged on the fifth postoperative day after becoming therapeutic on Coumadin. The patient lost 60 pounds, decreasing his BMI from 40.7 to 33.9. He is currently listed for a heart transplant.

\section{Case 5}

58-year-old male patient presented for evaluation for bariatric surgery. Patient had a LVAD placed one year prior to evaluation for ischemic cardiomyopathy. The patient was admitted five days prior to their planned bariatric procedure by the cardiology team and was transitioned from Coumadin to a heparin infusion. The patient then underwent an uneventful laparoscopic sleeve gastrectomy. There were no bleeding complications, and the patient was discharged home after being transitioned back to Coumadin and being optimized from a heart failure standpoint. He has lost 26 pounds in the three months since surgery to date, decreasing his BMI from 44.7 to 39.6. He has demonstrated improvement in his Diabetes control and continues to lose weight in hopes of being able to be evaluated for a transplant.

\section{Discussion}

Bariatric surgery is increasingly being used as a bridge to surgery in morbidly obese patients being evaluated for cardiac surgery. In patients that may require heart transplantation, patients are often required to have a BMI under 35 prior to being listed [6]. Morbidly obese patients with ventricular assist devices present a challenge, in that these patients have poor underlying cardiac function and are therapeutically anticoagulated. Bariatric surgery patients are at risk for both intraluminal and extraluminal bleeding, and perioperative therapeutic anticoagulation increases that risk. However, in our case series, there were no patients that suffered bleeding complications despite very little interruption in therapy. This supports previously published data of the safety of bariatric surgery in chronically anticoagulated patients [7]. Bariatric surgery appears to benefit these patients with advanced heart failure, as two patients went on to receive a heart transplant, one patient is now listed for a heart transplant, one patient had significant improvement in ejection fraction, and the last patient is continuing to lose weight and demonstrate improvement in 
diabetes management four months out from his procedure. Other studies have also demonstrated that bariatric surgery does not only induce weight loss to fit eligibility criteria for heart transplant, but can dramatically improve cardiac function, and in some instances obviate the need for transplantation $[8,9]$.

\section{Conclusion}

This case series demonstrates that bariatric surgery can be safely performed in patients with advanced heart failure using careful planning. Even with very little interruption in therapy, no bleeding complications were seen in these cases. Bariatric surgery can potentially help morbidly obese patients with advanced heart failure improve cardiac function or become transplant eligible.

\section{References}

1. Ribaric G, Buchwald JN, Mc Glennon TW (2014) Diabetes and Weight in Comparative Studies of Bariatric Surgery vs Conventional Medical Therapy: A Systematic Review and Meta-Analysis. Obesity Surgery 24(3): 437-455.

2. Lu JCY, Grayson AD, Jha P, Srinivasan AK, Fabri BM (2003) Risk factors for sternal wound infection and mid-term survival following coronary artery bypass surgery. European Journal of Cardio-Thoracic Surgery 23(6): 943-949.

\section{ISSN: 2574-1241}

DOI: $10.26717 /$ BJSTR.2019.22.003749

Mujjahid Abbas. Biomed J Sci \& Tech Res

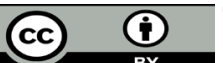

This work is licensed under Creative Commons Attribution 4.0 License

Submission Link: https://biomedres.us/submit-manuscript.php
3. Tyson GH, Rodriguez E, Elci OC, Koutlas TC, Chitwood WR, et al. (2007) Cardiac Procedures in Patients with a Body Mass Index Exceeding 45: Outcomes and Long-Terms Results. Annals of Thoracic Surgery 84(1): 3-9.

4. Ghanta RK, La Par DJ, Zhang Q, Devarkonda V, Isbell JM, et al. (2017) Obesity Increases Risk-Adjusted Morbidity, Mortality and Cost following Cardiac Surgery. Journal of the American Heart Association 6(3).

5. Vest AR, Heneghan HM, Agarwal S, Schauer PR, Young JB (2012) Bariatric surgery and cardiovascular outcomes: a systematic review. Heart 98(24): 1763-1777.

6. Mehra MR, Canter CE, Hannan MM, Semigran MJ, Uber PA, et al. (2016) The 2016 International Society for Heart Lung Transplantation listing criteria for heart transplantation: A 10-year update. The Journal of Heart Lung Transplantation 35(1): 1-23.

7. Mourelo R, Kaidar Person O, Fajnwaks P, Rao PE, Pinto D, et al. (2008) Hemorrhagic and Thromboembolic Complications after Bariatric Surgery in Patients Receiving Chronic Anticoagulation Therapy. Obesity Surgery 18(2): 167-170.

8. Mc Closkey CA, Ramani GV, Mathier MA, Schauer PR, Eid GM, et al. (2007) Bariatric surgery improves cardiac function in morbidly obese patients with severe cardiomyopathy. Surgery for Obesity and Related Diseases 3(5): 503-507.

9. Lim CP, Fisher OM, Falkenback D, Boyd D, Hayward CS, et al. (2016) Bariatric Surgery Provides a "Bridge to Transplant" for Morbidly Obese Patients with Advanced Heart Failure and May Obviate the Need for Transplantation. Obesity Surgery 26(3): 486-493.

AIOMEDICAL
RESEARCHES $\quad \begin{aligned} & \text { Assets of Publishing with us } \\ & \text { - Immediate, unrestricted online access }\end{aligned}$

